\title{
ORDE DEL CISTER
}

\author{
Magda Juncosa i Isabel de la Parte \\ DEPARTAMENT D'ANTROPOLOGIA SOCIAL I FILOSOFIA \\ UNIVERSITAT ROVIRA I VIRGILI. TARRAGONA.
}

\section{Histdria: orígens, fundació $\mathrm{i}$ expansió}

El Císter fou fundat l'any 1098 pel benedictí Robert, abat de Molesme, encara que va ser sant Bernat (1090-1153) el seu predicador i tedleg més important. El Císter va sorgir contraposal a la riquesa, la complexitat de la vida, la solemnitat litúrgica i l'esplendor de Cluny. Els cistercencs cerquen una vida més austera i fidel a la Regla de Sant Benet. Es un intent de tornar a les fontsi a la simplicitat de la Regla portant una vida senzilla caracteritzada per l'austeritat. La Regla fov abraçada per diverses comunitats, però no va ser fins al s.XI que sant Benet d'Aniana li dóna l'impuls definitiu. Des d'aquest instant ja es pot parlar d'orde benedictí pròpiament dit. D'aquest en sorgiren dues branques: la primera neix al monestir de Cluny i la segona a Citeaux, la qual donarà origen a l'orde del Císter. La primera edificació cistercenca és de l'any 1099.

El monestir de Vallbona de les Monges fou fundat a la primera meitat del s.XII. S'inicia com una comunitat mixta d'ermitans on l'autoritat màxima era l'anacoreta Ramon de Vallbona, però no es té la certesa de si eren benedictins. La documentació més antiga data de l'any $1153 \mathrm{i}$ no va ser fins a l'any 1175 que l'orde es va convertir exclusivament en femení incorporant-se a Císter i seguint la clausura monàstica fins aleshores.

L'any 1176 arriben a Vallbona algunes monges de la mà d'Oria Ramírez, abadessa vinguda de Tulebras (Navarra), i es fundarà la primera comunitat del nou orde en terres hispàniques. En aquesta època les abadesses havien de pertànyer a la noblesa. Amb 800 anys d'existència, hem de dir que Vallbona ha acollit quasi 80 abadesses.

Durant els tres primers segles, la comunitat gaudí d'una gran expansió; fins a principis dé s.XV hi havia permanentment unes 200 religioses. Es promogué l'establiment de pagesos a tota la contrada i es fundaren diverses poblacions i granges, havent hagut de dessecar la vall, fins aleshores pantanosa $i$ insalubre. El cenobi prestà sovint hostalatge a reis i a llurs corts i fou motiv d'inspiració de trobadors. L'abadessa era senyora jurisdiccional de diversos pobles i llocs.

Al s.XVI, arran del Concili de Trento (1545-1563), el monestir passa a regir-se a la clausura papal: "instauració del torn per a comunicar-se amb l'exterior, vel que els tapava la cara, prohibició de sortir de la clausura...En aquest Concili, també es promulgà una norma per la qual els monestirs de monges no podien estar aïllats i havien de romandre al costat d'una població'

\footnotetext{
1 Una estada breu, al novembre del 1992, a Vallbona de les Monges ens va oferir la possibilitat de conèixer i realitza entrevistes d'orientació biogràfica a tres germanes, que juntament amb les nostres observacions ens han permès elaborar les pàgines que ens ocupen a continuació. La nostra intenció es lluny que aquestes siguin definitòries, però sí que ha de servit com una mena d'apunt etnogràfic del transcurs diari d'un monestir de clausura avui dia. Agraïm a totes les "veïnes" de Vallbona la seva cordial rebuda, i molt especialment a aquelles que ens van dedicar part del seu temps, entre les hores de pregària, fent-nos còmplices de les seves experiències $i$ inquietuds.
} 
(Altarriba, E. i Baluja, J., 1990:98). A causa d'aquest decret tridentí que prohibia que els cenobis de monges fossin en despoblat, aquestes demanen als habitants de Montesquieu (poble molt a prop de Vallbona) que fundessin el poble dins el clos monàstic i l'any 1573 es forma una vila al voltant del monestir.

No és fins al Concili Vaticà II (1962-1965) que es permet una major llibertat "per facilitar la inserció de la comunitat a la societat moderna" (Altarriba, E. i Baluja, J., 1990:99).

Aquest monestir, juntament amb Poblet i Santes Creus, formen l'anomenada Ruta del Císter. Són construccions del s.XII que han acollit diverses comunitats. Actualment, a Santes Creus no hi ha cap comunitat, mentre que a Poblet hi viu un orde masculí i a Vallbona un de femení, essent aquest darrer l'únic on mai s'ha interromput la vida monàstica, exceptuant el període de la Guerra Civil Espanyola.

Els monestirs filials de Vallbona són el de sant Hilari de Lleida, el de Bon Repòs, a la Morera de Montsant, la Saïdia de València, el de Valldonzella de Barcelona, i hom li atribueix també la fundació del de Vallverd, a Tragó de Noguera, el del Pedregal, al Talladell, el de les Franqueses, a Balaguer, i el de la Bovera, a Guimerà.

Avui dia, Vallbona de les Monges és un poble amb 150 habitants, dels quals 22 són monges.

\section{Doctrina: tipologia i creences}

La comunitat cistercenca de Vallbona de les Monges s'acull a la Regla de Sant Benet, la qual presenta un conjunt de normes destinades a orientar la vida dels monjos per viure l'ideal evangellic, que consisteixen bàsicament en "ora et labora" i portar una vida contemplativa de pregària per Déu. La Regla, que va ser escrita al S.VI, consta d'un pròleg i de 73 capítols, la majoria de caràcter legislatiu, els quals regulen la vida quotidiana i tot el comportament benedictí.

Sant Benet parteix de la tradició cristiana, el credo de la qual abraça tota la humanitat i es basa en el precepte de l'amor. Tot es resumeix a estimar Déu i el proīsme com a un mateix. Déu és el creador de tot i l'home, que va ésser fet a la seva imatge, és la culminació d'aquesta creació. La fe és la forma cristiana de l'adhesió religiosa, i és essencialment fe en la persona de Jesucrist i en les seves ensenyances: la seva divinitat, la seva resurrecció i la promesa del seu retorn a la culminació dels temps, salvant de la mort aquells que han contestat la seva trucada. Les Escriptures són el document de la fe cristiana, formades per l'Antic i el Nou Testament, format a la vegada per quatre evangelis que constitueixen el relat de la vida i les ensenyances del fundador. En aquí es fonamenta una moral cristiana basada en la relativització dels béns terrenals com expressió concreta de la disponibilitat del seguiment de Crist, $i$ en l'apreci als pobres $i$ humils com a destinataris de l'amor de Déu.

Deixant a banda la tradició de què procedeix la institució religiosa benedictina, passarem a centrar-nos en les funcions i les creences d'aquesta comunitat en concret; diem funcions i creences perquè pràctica i teoria convergeixen constantment: l'escala de valors del codi benedictí desemboca en pràctiques determinades.

Es pot dir que el monaquisme és una posada en pràctica del cristianisme. Els primers cenobis cerquen "uns mitjans que ajudin a defugir del pecat i a començar a viure la salvació ja a la terra mitjançant la pregària, la caritat $i$ la pacificació interior. (...) Les regles monàstiques no voldran ser sinó una actualització de l'Escriptura per als qui han rebut la crida a viure'n a fons" (Dalmau, B. 1987:7). Podríem dir que els monjos són cristians més radicals que porten la seva fe fins al límit. Tedricament no divergeixen de la resta de cristians, perd en la pràctica no tenen res a veure amb els cristians seglars. "El monasterio ofrece otra posibilidad de maduración a base de una vida serena, honrada consigo misma, y reflexiva" (Altisent, A., 1990:23). Es a dir que la mentalitat cristiana és comuna a tots, mentre que les activitats, no.

Probablement l'austeritat és el punt de partida de la moral benedictina, a partir de la qual 
sorgeixen la resta de preceptes. Fent una llista dels conceptes que formen part del codi i que actuet de virtuts monàstiques o actituds espirituals trobem: la simplicitat o senzillesa, el silenci, l'obediència, la castedat, la pobresa, l'hospitalitat, la compunció, l'escoltar, la humilitat, la veritat, la puresa, l'estabilitat, la llibertat, entre altres.

L'objectiu d'un monestir benedictí és ésser una casa de pau i la del monjo ser un canal pel qual Déu transmet aquesta sensació. La vida del monjo és de gratuïtat intentant ésser fidel a Dé vivint en pau, pregària i simplicitat. Es podria afirmar que el monjo es posa en contacte amb Dé mitjançant la pregària i, llavors, Déu actua: "no és una pregdria concreta d'una cosa concreta, sinó que tu pregues perquè hi hagi més comunió amb Déu en el món, perquè l'amor de Déu passi als homes". La missió del monjo és pregar perquè Déu faci el que vulgui a través d'ell: "en aquest món tenim una missió de pau, trametre tot el que es pugui de Déu, perd̀ no tant en paraules,(...) $i$ el que he de mirar és que la meva vida estigui plena de Déu". ${ }^{2}$

La unitat és un concepte que entronca directament amb 1"ora et labora": "sant Benet no vell aixd d'ara treballo, ara prego, ara faig allo, ara aixd, sino que ell veu que quan l'home treballa, d'alguna manera continua portant en el cor a Déu (...) no trenca. Té uns moments més forts que són els de pregària, moments de l'ofici divi de litúrgia (...) Tota la vida ha de ser un pregar i treballar, que no es trenqui mai aquest clima, aquesta unió amb Déu, que és l'única cosa qu realment el monjo ha de fer, aquest portar Déu en el cor $i$ passi als altres. Excepte per a aixd el monjo no serveix per a res més, és que no ha de servir per res més, ja hi ha gent més especialista. (...) El monjo és canal de la voluntat de Déu".

Déu és una constant en la vida del monestir. Estan convençudes que Déu es troba a tơ arreu, que és omnipotent i que és sinonim d'amor: "Déu ens estima i Déu és amor (...) si tu estimes una persona, realment estimes Déu (...). El problema és que la gent no ho coneix (...). Déu és la simplicitat absoluta, Déu és aquesta bondat, bellesa, harmonia (...). El problema ens el creem els homes, que fem una imatge de Déu a la imatge de l'home i això no lliga". Afirmen que Déu dóna llibertat i que és molt respectuós: "la llibertat que Déu dóna, no la dóna cap home". Déu és infinit i per això no es pot demostrar la seva existència: "qualsevol cosa demostrable és finita gràcies a Déu, Déu és infinit en tot".

Afirmen renunciar a moltes coses per amor a Déu, però com s'entén aquesta renúncia? "Vivir es escoger (...), y escoger es abandonar y renunciar (...) la renuncia es ley universal en toda actividad. Lo que hay que plantearse es si merece la pena renunciar a lo que renunciamos los monjes" (Altisent, A., 1990:24). Un monjo renuncia a una vida familiar a canvi d'una vida en comunitat, "perd̀ és una renúncia en positiu, (...) per amor a Déu faig unes coses $i$ en deixo de fel unes altres que són ben licites".

Tot el codi doctrinari desemboca en l'entrega total i absoluta a Déu: donar-se, posar-se en mans de Déu, deixar d'ésser un mateix per ser el que Déu vulgui, trobar-se amb Déu, etc., són asseveracions que es reprodueixen constantment en un monestir.

\footnotetext{
${ }^{2}$ Es pot dir que és un orde passiu mancat de funció social, si el comparem per exemple amb altres ordes de servei a necessitat. Es manifesten en desacord amb l'eficiència i afirmen no tenir cap funció específica i alhora tenir-les totes: "no faig res concretament aquí $i$ ho faig tot. Potser puc fer més, més obra social jo que un altre, però jo no la veuré ni m'interessa, perquè crec que la fa Déu a través meu. (...) segur que això porta un bé a la humanitat, jo no sé on, tampô em preocupa massa, però sé que el porta". Les residents de Vallbona no tenen cap objectiu concret actiu ni eficaç. Veiem que mitjançant la pregària es pot buscar pau i espiritualitat, però no és aquesta la finalitat: "si una persona ve aquí $i$ se'n va millor, ho celebro, però no és aquesta la meva missió concreta de venir a ajudar a una persona concreta (...), si aquí bi ha pau, ella marxarà diferent, no sé, és una mica complicat".
} 


\section{Organització interna: càrrecs i oficis}

Originàriament, el gran nombre de fundacions cistercenques feren necessària l'adopció d'una normativa que contribuis a la cohesió dels diferents monestirs. Va ésser llavors quan es va elaborar la Carta de Caritat, que contenia uns reglaments i una constitució amb l'objectiu d'establir unes normes d'organització, per garantir la uniformitat dels usos i costums que havien de portar cap a una comunitat de vida de les diferents comunitats (1990:12). Al mateix temps, es creava el Capttol General, organisme de direcció i control espiritual que reunia els abats i les abadesses dels diferents monestirs. Amb el pas del temps, si bé l'esperit de la Carta de Caritat i del Capítol General es manté viu, no la seva forma originària. Pero, com s'organitza avui dia la vida a la congregació religiosa de Vallbona? Deixem que siguin els mateixos membres de la comunitat els qui ens ho expliquin.

Els monestirs cistercencs són totalment autònoms, independents en el govern i l'economia, però conformen una federació per poder-se ajudar, comunicar i estimular ${ }^{3}$. Vallbona de les Monges, igual que altres comunitats, respon a una estructura jeràrquica, amb la mare abadessa com a màxima autoritat: "és com una mena de guia, de pare espiritual per aglutinar, per orientar; la gràcia és agermanar les coses bones que tots portem", ens comenta una monja. La seva autoritat, però, transcendeix del terreny espiritual i s'instal la en els aspectes més mundans d'ordre i organització interna. Però la mare abadessa no és percebuda com una autoritat, en part a causa de la forma en què és elegida: "La votem nosaltres -ens explica la més jove de Vallbona- i dura 6 anys. Cada 6 anys fem l'eleccio; pot repetir la mateixa o una altra. Allavorens ella es tria dues col-laboradores: la priora i la subpriora. I hi ha tres monges, que les vota la comunitat, que fan de conselleres. I elles fan el Consell de la Comunitat. En les coses més ordinàries, la mare abadessa pot consultar a la priora. I si la mare abadessa se'n va, la priora fa les seves funcions, i si no la subpriora".

Així doncs, el Consell de la Comunitat, encapçalat per la mare abadessa, s'encarrega de l'organització diària del monestir, com ara el repartiment de les "tasques domèstiques" que es realitzen en comú. L'obediència a l'abadessa és part de la disciplina interna i cap membre de la congregació la discuteix ${ }^{4}$. Les monges no perceben la seva organització com a jeràrquica en la mesura en què totes es troben sotmeses per igual a una autoritat que elles mateixes han elegit. Tant la mare abadessa com la mare priora han de gaudir d'una major experiència espiritual i comunitària, per tal de poder-la transmetre a la resta de la congregació: "Es part d'una educaci $\sigma^{\prime}$, ens comenta una monja. Sovint són les més grans les que detenen aquest càrrec, i és que "les monges grans parlen amb Déu com qui parla...", ens comentava una monja joveneta. Aquestes, juntament amb la mestra de novícies, han de familiaritzar les germanes més joves amb la vida comunitària i religiosa.

Un altre càrrec significatiu a la comunitat és justament el de mestra de novícies, que adquireix la funció d'iniciar les postulants. La seva tasca es concreta en un seguiment de la trajectòria de la novícia i en la seva preparació per a una vida comunitària d'oració i de treball, és a dir, la preparació i la instrucció. Però seran la mare abadessa i la comunitat qui decidiran en última instància si aquesta pot assolir la professió solemme. I és que, amb relació a tots aquells aspectes que poden modificar o determinar l'ordre i la convivència internes, és tota la congregació qui ha de decidir mitjançant una votació.

\footnotetext{
${ }^{3}$ Una monja ens parlava d'aquesta ajuda i comunicació: "Fem cursets junts i a vegades celebrem coses juntes. Per la celebració del IV Centenari de la Basilica de Montserrat ens van convidar a tots els monestirs de Catalunya. I trobes gent de la teva edat, monjos i monges que tenim els mateixos problemes. I tots coincidim en que hi ba molta feina".

4 "La mare abadessa distribueix la feina $i$ el temps de dedicació i s'ha d'obeir. No es que anul-li la nostra personalitat, sinó que nosaltres ens volem alliberar del nostre egoisme*, ens confessa una monja.
} 
Finalment, hem de distingir, pel que fa a l'organització, aquests càrrecs de mare abadessa, priora, subpriora, conselleres i mestra de novicies, amb un cert caràcter espiritual, dels oficis com el d'hostatgera, portera -abans la tornera- o cuinera. L'hostatgera, per exemple, és la responsable de l'hostatgeria, peça fonamental en l'articulació de la comunitat. Recordem que sant Benet considerava l'obligació d'acollir l'hoste. Aquesta estança està pensada com un espai per al descans i la reflexió, i està oberta a tothom qui vulgui apropar-s'hi. Les monges dediquen una part important del seu temps a atendre els visitans: tenen cura de l'hostatgeria, preparen els diferents àpats del dia i estan a la disposició de tothom que les requereix per mantenir una conversa o per donar un suport espirituals.

A diferencia d'altres èpoques, avui dia tots els membres de Vallbona de les Monges participen en les diferents tasques $i$ feines que pauten $i$ configuren el cada dia a la comunitat.

\section{Forma de vida: rutines quotidianes, economia i organització grupal}

"L'ociositat és enemiga de l'ànima, i per això els germans s'han d'ocupar a unes hores determinades en el treball manual $\mathbf{i}$ a unes altres també ben determinades en la lectura divina' (Capitol XLVIII. Regla de Sant Benet)

Com podem observar en aquesta cita, la vida del monjo està regulada per l'oració i d treball: "Ora et labora, lema que no es troba a la Regla i que, massa topicament, ha servit per caracteritzar l'existència del monjo benedictí" (Dalmau, B., 1987:174).

La Regla distribueix la jornada del monjo en temps de pregària comunitària (ofici divi, al qual es dediquen de quatre a quatre hores i mitja), de pregària privada (a devoció de cada monjo i més breu que l'anterior) i en temps de treball necessari per al funcionament del monestir.

Alguns autors han dit que "un aprofundiment en la Regla de Sant Benet, pero, fa veure que el binomi de pregària i treball hauria de ser completat amb un tercer element. En l'ordre dels principis seria potser el d'estabilitat, en tant que compromís englobant" (Dalmau, B., 1987:174 175).

Vegem, però, com es concreta aquest pregar i treballar, el qual actua com a absolut regulador del temps en el monestir: "Ens aixequem a dos quarts de sis $i$ a les sis anem a resa matines, que és el primer rés del dia". Els benedictins cistercencs tenen l'ofici de les hores, que consisteix a articular el dia en hores de pregària, en un ritme basat a resar i treballar. Les Matines duren entre mitja i tres quarts d'hora. De seguit es fa una hora de pregària personal, "cadascú lo pot fer on vulgui, a l'església, a l'habitacio, a l'hort si fa bo". A dos quarts de vuit s'esmorzai en acabar "a fer el llit $i$ a les vuit fem laudes $i$ a dos quarts de nou, l'eucaristia. Aixd, els dies laborables, $i$ per alla a un quart de deu ja anem a treballar, fins a tres quarts d'una". Cada monji tế una tasca assignada: unes estan dedicades a labors que porten endavant l'economia del monesti $\mathrm{i}$ altres a les tasques domèstiques. Vegem com es reparteixen la feina: "Per cuinar (...) n'hi ha tres de més fixes perquè els agrada més o en saben més (...). Perd, per exemple el diumenge, no cuinen, perquè no sigui tan pesat fer-ho cada dia i cuinem totes. Ens ho anem tornant una mica tot $i$ a l'hora de fregar els plats doncs...tothom: hi ha una llista $i$ va rodant, no es tracta de separar les que treballen en treballs domèstics $i$ les que fan treballs especialitzats, aixd seria masst bo. Les que estem a ordinadors $i$ a cerdmica sempre som les mateixes, però les feines domèstique van una mica repartides". A la una es comença la sexta, "després anem a dinar i després de dina fas els serveis que sigui, si has de rentar plats o el que sigui. Després queda una estona lliure fin

\footnotetext{
5 -Abans l'hostatgeria només era per a la gent que volia fer silenci, fer recés. Després, la gent jove i aixi ens va demanar per venir a preparar les oposicions $i$ ens ho vam parlar la comunitat, perquè nosaltres ho decidim entre totes. I va pensar que si era per fer un bé... Es una manera d'evangelitzar sense moure't de casa", ens explicava la més jove.
} 
a tres quarts de quatre, que es fa la nona, fins a les quatre, hora en què es comença la pregdria personal". De cinc a set és temps per treballar, a dos quarts de vuit es fan els vespres, a les vuit es va a sopar i a un quart de nou comença una hora de recreació "per parlar, per explicar-nos alguna tinguda, o si alguna vol comunicar alguna cosa a les altres, ens trobem totes plegades d'una manera informal, no en una reunió estricta; és una cosa de familia (...) ho fem en una sala i a l'estiu a l'hort 0 al claustre. Es una cosa completament distesa, amb algun acudit o el que et vingui de gust". A un quart de deu hi ha completes, el darrer rés del dia, i a prop de tres quarts de deu, ja és hora de dormir. Tenir totes les hores del dia regulades significa tenir el temps santificat.

Cada monja, segons quin sigui el seu càrrec, exercirà una feina determinada, feina que, com hem vist, varia el cap de setmana. L'hostatgera, per exemple, s'encarregarà de l'hostatgeria; la sagristana, de la sagristia; la cuinera, de la cuina; les porteres, de la porteria, etc. Se solen ajudar mútuament en casos en què hi ha més feina: "els diumenges vaig a donar un cop de mà a la porteria, a vendre a la botiga, ja que vénen molts turistes".

Aquesta quotidianeïtat $\mathrm{i}$ aquest repartiment del temps tan escrupolos es trenca si algun membre marxa un cert temps del monestir, cosa que poden fer si està ben justificat. Anys enrera estava totalment prohibit marxar del monestir i el contacte amb l'exterior era a través de reixes. "Hi ha algun monestir benedictt on probablement ens haurlem de veure entre reixes; en canvi nosaltres, grdcies a Déu, podem fer-ho al voltant d'una taula. (...) nosaltres sortim del monestir si cal, passa que aquest "cal" és una mica ampli. Jo vaig fer una carrera (...) Doncs ara, evidentment, no aniré a classes cada setmana; perd si de tant en tant hi ha algun curs interessant, doncs és logic que hi vagi, penso que és normal; l'ofici divt és important $i$ els meus estudis també son importants. Aqut les ceramistes, si han hagut d'aprendre alguna cosa, se n'han hagut d'anar tranquil lament (...). També tenim un treball d'ordinadors, hi treballo jo, doncs ldgicament he anat a fer els cursos que han calgut; ara, res més que aixd. Ara, no perquè em vingui de gust me n'aniré on sigui".

La quotidianeïtat també es transgredeix en períodes de vacances. Les monges fan sortides conjuntes a visitar diversos llocs.

Cada monestir és independent des del punt de vista econòmic i el treball per al sosteniment de l'empresa és obligatori per a totes les monges. Sant Benet insisteix en la productivitat reduïda a l'autoabastiment del monestir: "Si hi ha artesans al monestir (...), si mai un d'ells s'envania per la seva traça en l'ofici, perquè li sembla que porta algun guany al monestir, que aquest sigui tret de l'ofici (...). Si s'ha de vendre (...) mirin de no atrevir-se a fer cap frau (...). I que en els preus no s'infiltri el mal de l'avarícia" (Cap. LVII. Regla de Sant Benet).

Per posar en pràctica aquest autoabastiment, "en el seu inici, els monjos cistercencs viuen bàsicament i primordialment de l'explotació i comercialització dels productes derivats de l'agricultura i la ramaderia, practicada en les nombroses terres acumulades gràcies a les donacions de senyors i hisendats" (Altarriba, E. i Baluja, J., 1990:18). Segons la situació geogràfica, es troben unes 0 altres fonts de finançament; a Poblet i a Santes Creus, per exemple, es comercialitzava amb llana, i en aquelles contrades on era possible ho feien amb vi, mel, fruits, etc. Alguns monestirs estaven dedicats a la metal-lúrgia i fabricaven eines de ferro útils en el camp.

Els recursos economics de Vallbona provenien bàsicament dels productes de conreu i dels treballs manuals (de costura) realitzats per les monges. Vegem, pero, com ha canviat avui dia el treball del monestir, adaptant-se a les necessitats de la societat moderna: "Nosaltres ens guanyem la vida per l'orde, per al menjar $i$ el vestir, per si s'espatllen coses de tipus domèstic $i$ prou. Llavors tenim dues fonts d'ingressos: la cerdmica, perquè aqut hi ha turisme, sobretot els caps de setmana, hi ha una botiga, hi ha algunes comandes de persones (...). Tenim ordinadors $i$ fem tractament de textos, partitures de música, treballem per l'editorial Planeta $i$ altres editorials. Tenim quatre ordinadors $i$ una impressora làser. Per tant poden sortir els originals tal qual (...) $i$ no descartem tenir algun dia un offset, però aixd ja són més pessetes $i$ no arribem. (...) 
L'hostatgera en sap molt de fer ganxet, perd aixd̀ no és massa rentable (...) és més atractiu segon quin tipus de feina". Afirmen necessitar poc, ja que gasten molt poc, "no tenim necessitats, es pa passar amb molt poca cosa. (...) L'austeritat tracta de no tenir més necessitats de les que calen Tot és molt més simple, la vida és molt més simple".

El treball no es percep com una cosa rígida per mantenir un determinat nivell: "aquest mall hem anat cinc monges a collir fruita $i$ els ordinadors s'han quedat quietets, tranquils. (...) La monges no estem de cara a l'eficàcia, suposo que un economista o una gent aixt es feriria en ut monestirn.

Les monges acostumen a comprar a l'engròs, els surt més a compte ja que també han de proveir l'hostatgeria, on a vegades tenen més de $\mathbf{4 0}$ hostes. "Els majoristes que proveeixen les botigues del poble, passen pel monestir, on quasi fem més gasto que no pas les botigues. A vegades si ens falta alguna cosa l'anem a buscar a les botigues".

Disposar d'hostatgeria és una de les obligacions del monestir benedictí, ja que la Regla diu que "tots els forasters que es presenten han de ser acollits com el Crist (...) Tan bon punt s'avis que hi ha un foraster, el superior i els germans el sortiran a rebre amb tota l'atencio i la caritat. (...) Que es mostri la màxima sol-licitud en l'acolliment dels pobres" (Capítol LIII. Regla de Sant Benet).

En el moment en què es realitza aquest estudi, l'hostatgeria es troba en obres d'habilitació i provisionalment els hostes s'allotgen en un refugi que hi ha tocant al monestir. L'hostatgeria dóna al claustre, nau d'on sorgeixen la resta d'estances, com són les cel·les, on s'han disposat unes reixes "per problema de seguretat. En principi tothom és bo mentre no es demostri el contrari, les reixes són perquè d'alguna manera l'hoste no tingui accés a la comunitat". La permanència dels hostes no comporta cap canvi en la vida de la comunitat, ja que aquest fa vida paral lela al monestir sense implicar-se en la seva quotidianeïtat. L'hoste pot anar a les pregàries comunitàries, però no té accés lliure a les dependències monàstiques, les quals formen part de la vida privada de les monges. "Vosaltres tampoc deixarleu que ningú vingués a ficar-se a la vostra casa". Es a dir, que hi ha la part pública del monestir destinada a visites, siguin turístiques o d'un altre caire, i després es troba la resta de l'edifici que forma part de l'àmbit privat de clausura ${ }^{6}$, com és per exemple la cel-la. Cada monja disposa de la seva cel-la, les quals actualment es troben ruinoses: "l'arquitecte diu que ell no hi viuria, estan a punt de caure (...), fetes a principis del segle passat". Els estan construint cel-les noves "que seran més funcionals, amb lavabo, dutxa i wàter, no massa grans, llit, taula, cadira i armari, no necessitem res més".

Els hostes i les residents tenen horaris diferents en els àpats: primer mengen les monges $i$, en acabar, passen els visitants. Ja s'ha dit que no hi ha massa relació entre uns $i$ altres, sant Benet diu: "el qui no ho té manat no s'ajunti de cap manera ni parli amb els hostes; però si els troba 0 els veu, un cop saludats humilment (...) que passi de llarg dient que no li és permès parlar amb els hostes" (Capitol LIII. Regla de Sant Benet).

L'hostatgeria l'autofinancen els hostes, sense que el diner signifiqui un obstacle per a l'estada: "si algú no ho pot pagar, aixd no és un impediment perquè no pugui venir". No es treuen diners d'aquest servei, tan sols es cobreixen despeses.

Les monges perceben dos tipus de visitants: els turistes, "que vénen a veure el monestir de la mateixa manera que podrien anar a un altre lloc", i la gent que s'allotja a l'hostatgeria, "que solen ser persones que busquen".

La Regla diu que si el monjo a l'hora d'entrar en el monestir "posseeix béns, o que abans

\footnotetext{
${ }^{6}$ L'edifici cistercenc respon a la idea de vida en comú $i$ en oració. Tot ell està estructurat al voltant del claustre a partir del qual sorgeixen la resta d'estances on es porten a terme les tasques de la comunitat: es treballa a l'escriptori i biblioteca, la lectura de la Regla i altres actes comunitaris es fan a la Sala Capitular, s'ora a l'església, es menja al refetor i es dorm al dormitori. Tota la construcció cistercenca està creada d'acord amb la vida monacal, la qual transmet la seva austeritat a l'arquitectura (Altarriba, E. i Baluja, J., 1990:14-16)
} 
els distribueixi als pobres, o que amb una donació legal els cedeixi al monestir, sense reservar-se de res, com qui sap que des d'aquell dia no tindrà potestat ni sobre el seu propi cos" (Capítol LVIII. Regla de Sant Benet). Les monges de Vallbona manifesten les seves donacions a persones necessitades: "jo vaig donar la meva roba a aquells que els hi faltava"; i altres pertinences van ser cedides a la família, "vaig donar un tros de terra, on volia fer-me una casa, al meu germa". Per entrar en un monestir és indispensable no posseir res material, ésser desprès i "un pic has fet la professió solemne, ja no tens propietat privada, no tens béns". L'economia a nivell individual és inexistent, cap monja disposa de diners.

El manteniment de la construcció monàstica va a càrrec de la Generalitat: "nosaltres no podem mantenir un monument nacional".

Parlant de la imatge externa o "look" monàstic, hem de dir que durant la professió monàstica el monjo és despullat dels propis vestits i rep els del monestir. Quant a la indumentària de les monges, hem de dir que quan una dona ingressa en el monestir es vesteix amb hàbit. Els monjos cistercencs adopten l'hàbit blanc enfront els monjos negres de Cluny, "o més ben dit, de color cru, per considerar dins la rigidesa de les seves normes, que blanquejar la tela era ja un luxe superflu" (Altarriba, E. i Baluja, J., 1990:12). Avui dia els cistercencs van blancs amb l'escapulari negre.

L'hàbit crea unitat, "que no és el mateix que uniformitat, la vista hi reposa (...) és harmonia". L'hàbit no és percebut com a uniforme, "expressa la relació nova que té el monjo envers Déu i la comunitat" (Dalmau, B., 1987:115).

Per treballar no porten hàbit, sinó que utilitzen peces més funcionals com bates: "en els actes en què ens trobem la comunitat anem sempre amb habit, perd s'entén que un habit blanc, llarg fins als peus, per treballar, quedard maco al cap de cinc minuts, és logic. Llavors et poses una bata més curta $i$ simple". Disposen de dos hàbits, "no en necessitem més".

Quan surten fora del monestir, tenen llibertat per escollir la vestimenta. No solen portar hàbit, però tampoc solen anar de carrer sense cap distintiu de la comunitat.

Solen portar un vestit de monja més curt, "jo no tinc cap inconvenient de sortir de monja, tothom va com vol (...) penso que si cadascú surt com vol i amb coses ben estrafolàries, per què no hi puc sortir jo ? (...) No tinc per què camuflar-me (...), simplement surto de monja ja que no tinc per què amagar-me i si a algú no li agrada, doncs mira, tranquil. Jo puc sortir de seglar, però em sembla que és com voler camuflar el que sóc. (...) a vegades, si sortim de seglar, fem pena (...) llavors et poses de monja i quedes molt més endreçada". Els vestits els solen fer elles mateixes, a vegades ajudades per unes modistes.

"Quant a l'alimentació, la Regla indicava que s'havia de fer una única menjada al dia (...). Segons el pare Altisent de Poblet, la dieta alimentària dels monjos la constituïen ous, peix fresc $\mathrm{i}$ salat, verdures, formatge i fruita novella" (Altarriba, E. i Baluja, J., 1990:21).

A Vallbona mengen de tot, però practiquen l'abstinència els dimecres i divendres, dies en què no mengen carn. Tenen un temps anomenat de Quaresma, en el qual practiquen dejuni, "però ens deixen ben lliures, que cadascú ofereixi a Déu el que vulgui; parla amb l'abat i li diu que li va millor prescindir de l'esmorzar o d'un altre dpat". Solen menjar plats casolans i afirmen que el peix és congelat a causa del baix pressupost. De cafe només en prenen els diumenges i, a diari, cafe descafeinat. Tenen una ampolla de vi a taula "que comprem al sindicat del poble".

Totes les monges mengen el mateix, no es fan plats especials segons els gustos. Aquest fet provoca que al principi es faci difícil adaptar-se a la nova alimentació: "em va costar habituar-me (...) em vaig aprimar enormement $i$ vaig haver de sortir perque fisicament no aguantava (...). a mi no m'agradaven les bledes, les sopes, el pollastre, les patates (...) i anava passant el dia i no menjava res o ben poca cosa, fins que ho vaig intentar i ja el cos se'm va habituar". 


\section{Iniciació: la professió i la presa d'hàbit d'una monja}

"Vaig sentir la crida de Déu", ens deia una monja, " $i$ el moment de la crida et poses en mi de Déu". I és aquest el primer pas cap a un camí espiritual, és la crida a la iniciació.

La condició primordial per ingresar en un monestir és la recerca de Déu. El Codi de drá canònic manifesta necessari el celibat o la viduïtat per poder ser monjo. I en ingressar en d monestir es fa el vot d'estabilitat: "Jo, quan el faig, sé que viuré tota la meva vida aqu" . No i ha cap edat específica per entrar-hi, però s'aconsella no fer-ho abans dels 23 o 24 anys: "Aquestet coses s'han de pensar una mica $i$ abans d'aquesta edat falta decisio $i$ compromis".

La vida de clausura és planteja com un camí dur que necessita una forta preparaciói dedicació. Les monges no ho perceben com una renúncia, sinó com una donació i una entrega plenes. I per això l'adoctrinació està formada per etapes temporals de formació i espais provatoris La primera etapa és el postulantat, un període de prova, abans d'ésser admesa en l'orde, que sod durar entre mig any $\mathrm{i}$ any $\mathrm{i}$ mig: "Es un temps informal, com un impds, on es formen els engranatges". Després ve el novíciat, que dura any i mig com a mínim i dos anys i mig com ı màxim: "Es un temps fort de formació, d'estudi, de veure si la cosa realment funciona (....) després d'estudiar la Regla i d'estar en contacte amb la parròquia (...), veus si el que tu busques té algun contacte amb la vida monàstica". Després es fa el primer vot de compromís, la primen professió o professió simple ${ }^{7}$, que dura tres anys com a mínim i sis com a màxim, anys que es poden prorrogar: "Poden haver casos en què una s'ho estigui pensant durant 12 anys". I despres es prometen els vots definitius, la professió solemne, que significa agafar un compromís per a tota la vida, emetre els vots perpetus.

Però potser que recreem la professió d'una monja tal i com ella ens ho ha explicat, per aixl poder-nos apropar $i$ entendre aquest procès, aquest ritu de passatge. Es el cas d'una jove que acudeix amb unes amigues a l'hostatgeria $^{8}$ de Vallbona a passar un cap de setmana i que ens explica, des del present, la seva experiència passada. La primera impressió és molt significativa: "Van haver-hi dos coses que no tan sols em van impressionar, sinó que em van causar un impacte molt fort. Perque, bueno, vam anar a l'hostatgeria', que ara no existeix, $i$ vaig trobar l'ambien rural, molt senzill, com si anessis a casa de pagès. No sé, vaig trobar un ambient...et trobaves bé. Era gent normal, bueno la gent normal no era això, era gent contenta. De seguida et deien pel teu nom com si no hagués diferència entre elles $i$ jo. L'altra cosa que em va impressionar eren les vespres, em van impressionar molt, molt". La jove comptava amb 18 anys. Llavors va començar a modificar la seva vida introduint nous hàbits, preludi d'un canvi, d'una nova identitat: "I jo vais pensar: m'aixecaré al dematt, m'escalfaré un gotet d'aigua, a casa no teniem aigua calenta, i mentre s'escalfa l'aigua resaré un salm, que $m$ 'havien ensenyat, $i$ unes pregàries $i$ tal, $i$ aleshores llegiré un capítol de la Biblia". Però ella no ho percep com una transformació externa, més aviat interna: "Cada vegada m'anava trobant més bé en un clima de pau, en un clima de silenci"; que la va portar a demanar consell a algú que ella considerava que la podia orientar, a un monjo de Montserrat: "La plegària em sedueix d'una manera que...Allawòrens, ell em va dir: Què has pensat, en una vida activa o una vida contemplativa? No he pensat en res, però a mi això de la

${ }^{7}$ La professió és un acte jurídico-religiós pel qual s'abraça públicament i de manera estable la vida religiosa $\mathrm{i}$ hom es compromet a complir els vots propis de l'orde.

${ }^{8}$ A les entrevistes, l'hostatgeria es revela com una forma de "captacio" de noves vocacions: "(...) es queden, sempre és per l'hostatgeria (...) Ara, per exemple, hi ha 4 noies. Hi ha una monja que és mestra de novícies, i les hi fa un seguiment. De tant en tant vénen, parlen amb ells, llegeixen coses, amb una inquietud religiosa però sense un compromis" ens comenta una monja.

9 L'any 1991, l'hostatgeria romania tancada temporalment a causa d'unes reformes. 
vida activa no em va, perquè això que et destinen a..., em va més una cosa més quieta. Pues vida contemplativa. Quines monjes t'agraden? Jo, les de Vallbona. I que he de fer jo? Anar a Vallbona i parlar amb la mare abadessa".

La postulant, una vegada que opta per una vida religiosa, pot triar la congregació a què li agradaria pertànyer i demanar l'entrada a la mare abadessa. I s'inicia el procés d'admissió. Des d'aquest instant, és la mestra de novícies qui li farà un seguiment durant aquest impás a la vida monacal, primer com a postulant fora del monestir ${ }^{10} \mathrm{i}$ després com a novícia, ja admesa en la comunitat. Dos anys de novíciat i tres de professió simple configuren el seu espai temporal com a aspirant a la vida de clausura. Durant aquest temps porvatori i d'aprenentatge es trobarà sota la tutela de la mestra de novícies, que no sols la guiarà sinó que l'observarà per poder jutjar si està realment preparada per a la recepció de la clausura. Però abans de fer la professió solemne, la mare abadessa i la comunitat en ple hi han de donar el seu consentiment: "La mestra de novicies informa a l'abadessa, i la mare abadessa a la comunitat. I es fa un estudi psicoldgic abans d'entrar, per evitar la professí solemne, perquè després ja és per sempre". Avui dia s'ha incorporat al procés un estudi psicologic de les aspirants per evitar que siguin causes alienes a la fe les que portin cap una vida de clausura, ja que entenen que la vida comunitaria se sustenta en el convenciment de les persones que la componen. Després de la professió solemne, la monja s'incorpora plenament a la comunitat: "I a partir d'aqul, en tots els actes de la comunitat, s'ha de comptar amb tu. Tens veu $i$ vot".

Tot aquest procés comporta un ritual; si bé ja han quedat enrera el vestit de núvia i el tall dels cabells, encara es manté part de tot un ceremonial ple de simbolisme, que s'entén dins d'una vida molt ritualitzada. "La professió d'una monja és una festa", ens comenta una monja, "sempre es fa dins l'eucaristia, la professió simple després de l'homilia (...); vas allà enmig i la mare abadessa et pregunta: A què has vingut?". La monja ha de contestar a la vegada que porta la carta de professió, escrita prèviament, on es compromet a viure com a monja en una vida de celibat, d'obediència i de promesa, i que ha de firmar davant de l'altar, del capellà que presideix la ceremònia i de tota la comunitat: "Aleshores t'agenolles davant de la mare abadessa $i$ li prometes. Ella obre les mans $i$ tu li poses dins. I després d'això et posen l'hàbit $i$ continua l'eucaristia. Després es fa un dinar més bo $i$ vénen els familiars". Es una celebració. La cerimonnia de la professiò solemne és molt semblant: "Després de l'homilia t'estires a terra, representa que mors a l'home $i$ neixes al nou. Es el simbol del bateig. I mentre estàs estirada a terra, es canta la Lletania del Sants. Hi ha un ritual, uns sants que es proposen, $i$ tu pots proposar els sants que et facin més devoció. Jo vaig molt directa a Déu, perd sempre hi ha un sant o un altres que et fan més grdcia". I la monja torna a renovar els vots, però aquesta vegada per sempre. La mare li imposa la cogulla com a símbol de la comunitat. Finalment, "ella t'abraça en representació de tota la comunitat". Es el símbol de l'acceptació i la rebuda a una nova vida.

\section{Relació amb altres institucions socials}

"La gent no t'entén, pensen que és com enterrar-te en vida". Potser aquestes paraules d'una monja exemplifiquen la percepció que encara es té de la clausura. Però elles no ho senten així.

La professió solemne implica un trencament i un compromís. Un trencament amb la vida anterior, ja que són moltes les coses que es deixen enrera: una familia, uns amics, una feina, uns hàbits...; a la vegada que comporta un compromís amb una nova familia, unes noves relacions, una nova feina, uns nous hàbits....Elles ho comparen amb el matrimoni: "Et cases $i$ renuncies a moltes

\footnotetext{
${ }^{10}$ Aquesta jove ens parlava d'aquest període: "Em van fer llegir llibres i tal, perquè jo no sabia, els de la Regla de
} Sant Benet i els de vida espiritual". 
coses". Però això no necessàriament significa una total desvinculació amb el món que les envoli "Penso que en el monestir hem d'estar informades de la societat, però sense que la societat a xucli"; això si, s'ha de mantenir una certa reserva: "Es una reserva i tothom la té a casa, resert per a la vida de silenci i plegdria". Es part de la vida contemplativa.

El tancament que implicava la clausura de temps passats ha quedat enrera. La possibilit de sortir fora del monestir o d'anar-hi facilita el contacte amb altres instàncies socials.

Les biografies realitzades revelen d'alguna forma que el major distanciament es dóna eni moment de prendre la decisió de fer-se monja i durant el noviciat; i dos fets semblen ésser la cau d'aquest allunyament. Per una banda, la incomprensió que sol acompanyar una decisió d'aqus tipus: "A la familia li va costar molt. En certa manera la gent et dóna l'esquena. No ho entenen:" I per altre, la rigidesa del noviciat. El temps d'instrucció és molt sever i significa una toe dedicació a la lectura i a la pregària. Però, una vegada la novícia s'ha emmotllat a la nova situací resorgeix el contacte: "(...) després, amb els anys, la gent s'adona de que la vida dóna més des $i$ que tot és relatiu", encara que hi ha una redefinició de les relacions: "Ara, la nostra vida ést vida de comunitat $i$ la familia està a un altre nivell". Avui dia, a la monja se li permet acudir determinats esdeveniments familiars com ara la mort d'un parent o l'assistència en cas de malalti I hem d'insistir en la possibilitat sempre present d'acudir al monestir $\mathrm{i}$ visitar les seves habitants

Per altra banda, el major o menor contacte amb l'exterior està en funció de les activitats d les monges. Per exemple, algunes monges cursen estudis a ciutats properes ${ }^{11}$, desplaçant-1 periodicament fora del monestir. En el mateix sentit, el desenvolupament de les feines d'edició d textos, que actualment suposen una important font d'ingressos per a la comunitat, així com I comercialització de l'artesania que elaboren, impliquen una relació econòmica amb altres entitats

També les vacances poden interpretar-se, sinó com una forma de relació amb altre institucions socials, sí com un trencament de la rigidesa de la vida monàstica: "Sortim una setman a l'any. Anem de vacances la comunitat, en grup. Es un descans, un trencament amb la vid ordindria". La muntanya i la platja són els llocs triats per al descans i el relaxament. I és una pron més d'una redefinició de la vida cenobítica.

Ja hem esmentat, i potser no seria necessari tornar-hi però hi insistim, que hi ha una relaci contínua amb altres comunitats religioses, especialment amb les cistercenques: "A vegades fen cursets. I hem conegut altres monestirs perquè ara ja no fem vida de clausura".

Finalment, hem de tenir present que l'actual ruta turística del Cister $^{12}$ ha originat qu Vallbona de les Monges esdevengui un punt de trobada i un oferiment social ${ }^{13}$. Cada dia arribx gent que serveix d'enllaç comunicatiu d'allò que s'esdevé fora del monestir.

\section{A manera de conclusi 6}

Abans les moges només podien comunicar-se amb l'exterior mitjançant el torn; fins i tot pe a moltes d'elles aquesta imatge ha quedat allunyada en el temps. Ara, la vida de cenobi ha ober la seves portes, no per deixar entrar sinó per deixar sortir.

Podem dir que Vallbona ha patit un procés de transformació al llarg de la història, s'ha

11 Actualment existeix la possibilitat de realitzar cursos i aprenentatges, com és el cas d'una monja que estudia música a Barcelona, però s'ha de comptar amb el permís de la comunitat, que abans de decidir valora la seva utilitat.

12 Poblet, Santes Creus i Vallbona i les seves filials conformen la ruta del Cister a Catalunya.

13 Una monja ens feia la següent reflexió: "Si jo ofereixo el mateix que la societat, sempre ho faré pitjor (...) monestir ha d'oferir un altre tipus de cosa (...) per gent que sense creure puguin venir a trobar uns dies de repòs, de pau de serenitat (...) no perquè vinguin a veure la tele (...), que d'hotels amb camps de tennis $i$ bingo ja n'hi ha molts". 
adaptat en certa mesura a les noves exigències o així ho creuen elles: "La societat ha canviat $i$ nosaltres també hem caviat". Si pensem, per exemple, en l'aillament social que anys enrera comportava la clausura, observem que el monestir de Vallbona ha esdevingut més aviat un centre social i turístic. I ara la clausura interna és percebuda per les monges com un espai de privacitat: "Nosaltres necessitem certes estones $i$ certs espais $i$ no podem permetre que d'alguna manera les necessitats de la societat, que no són necessitats evidentment transcendentals o importants, ens col-lapsi la nostra vida, perquè llavors el monjo no tindria cap sentit".

Però, què és el que pot motivar que una dona s'orienti cap a una vida monacal? Potser no hi ha una única causa; potser només és "el desig de Déu", com elles diuen. El cert és que la fe és dificilment descriptible: "sembla que ho hagis de concretar, però a l'hora de concretar-ho s'escapa de les mans". No totes elles havien estat educades religiosament: unes hi han entrat jovenetes $\mathrm{i}$ altres de grans; algunes provenen d'altres ordes ${ }^{14} \mathrm{i}$ altres no en coneixen cap més. No hi ha un trets sociologics comuns -o nosaltres no els hem percebut- que ens ajudin a entendre aquesta opció. Es la vida comunitària, un estil de vida compartit i fonamentat en la uniformitat; uniformitat no tan sols externa, d'aparença, sinó també de caràcter, de tracte: "Has d'aprendre a callar. Es una vida de silenci. Costa molt. Has d'anar fent vida interior". Sembla com si la clausura adquireix una funcionalitat a nivell psicologic intern: "Et dóna una confiança (...) He guanyat molt a Vallbona". Però no és una experiència positiva per a aquelles que, havent-hi estat, en surten desencantades i fan una lectura negativa del seu pas i per justificar seva sortida. Per a les monges, les causes són obvies: "Un comença amb molta il-lusio i la feina que tens és matenir-la tota la vida". I és que les parets de la clausura entranyen una percepció diferent de l'espai, del temps i de la vida en general per a la qual no tothom està preparat. ${ }^{15}$

\section{BIBLIOGRAFIA}

ALTARRIBA, E. / BALUJA, J.

1990 L'Orde del Ctster a la Catalunya Nova. Caixa de Tarragona.

ALTISENT, A.

$1990 \quad$ Reflexiones de un monje. Pedal/Sígueme.

DALMAU ,B.

1987 Lexic d'espiritualitat benedictina. Publicacions de l'Abadia de Montserrat.

JUST, C. M.

1989 Regla de Sant Benet. Publicacions de l'Abadia de Montserrat.

\footnotetext{
${ }^{14}$ Com és el cas d'una monja que després d'haver passat part de la seva vida a Sud-amèrica en servei actiu, va decidir retirar-se a una vida contemplativa.

${ }^{15}$ No podem finalitzar aquesta breu monografia sense fer un petit pero important aclariment: l'abertura de la clausura que s'ha produït després del Concili Vaticà II (1962-1965) no ha arribat a tots els monestirs: encara n'hi ha que mantenen el toro com a única vinculació amb l'exterior.
} 